\title{
Valence, Voice, and Noun Incorporation in Karajá
}

\author{
EDUARDO RIVAIL RIBEIRO \\ University of Chicago
}

\section{Introduction}

The purpose of this paper is twofold. ${ }^{1}$ First, it provides a brief description of the morphosyntax of Karajá, a Macro-Jê language spoken in Central Brazil, focusing especially on the mechanisms of valence marking and grammatical relation changing. In addition, this paper discusses the implications of the Karajá data for Baker's (1988) incorporating account of antipassive. Karajá is traditionally described as having a very irregular fused set of prefixes indicating person, aspect, object, and direction (Fortune and Fortune 1964, Wiesemann 1986, Maia 1998). However, a more careful analysis reveals a rather regular, mostly agglutinating morphology, with separate prefixes indicating person (and, cumulatively, mood),

\footnotetext{
${ }^{1}$ I would like to thank the Wenner-Gren Foundation for Anthropological Research, the University of Chicago, and the Brazilian National Scientific Development Council, CNPq (Grant 200018/981), for their financial support. I also owe special thanks to the Karajá speakers for kindly teaching their language to me and to Neha Dave and Victoria Marty for their encouragement. Amy Dahlstrom provided valuable suggestions on an earlier version of this paper, for which I am very much indebted. Any remaining mistakes are, of course, my sole responsibility.

Karajá is spoken along the Araguaia River, in the states of Goiás, Mato Grosso, Tocantins, and Pará. It has four mutually intelligible dialects: Southern Karajá, Northern Karajá, Javaé, and Xambioá. The language presents systematic differences between male and female speech. Female speech can be postulated as the basic one. Male speech is characterized by the deletion of a velar stop occurring in the corresponding female speech form (e.g. + dikarz̃ 'I' > $\hat{\jmath}$ drarã). Unless otherwise noted, the data in this paper are from the female speech of the Southern and Northern Karajá dialects, but the grammatical features presented here are common to all four dialects. The data, obtained from native speakers in several fieldtrips, are presented both in phonetic (first line, in italics) and phonological transcription (second line). For details on the phonology, see Ribeiro (2000a).

Abbreviations and symbols: $q=$ female speech, $\hat{\delta}=$ male speech, $\mathrm{ADM}=$ admonitory, $\mathrm{AL}=$ allative, $\mathrm{ANTI}=$ antipassive, $\mathrm{CAUS}=$ causative, $\mathrm{CTFG}=$ centrifugal direction, $\mathrm{CTPT}=$ centripetal direction, FUT $=$ future, IMPERF $=$ imperfective, INSTR $=$ instrumental, INTR $=$ intransitive, LOC $=$ locative, $\mathrm{NARR}=$ narrative particle, $\mathrm{PASS}=$ passive, $\mathrm{PERF}=$ perfective, $\mathrm{PROGR}=$ progressive, $\mathrm{REFL}$ $=$ reflexive, $\mathrm{REL}=$ relational prefix, TRANS $=$ transitive, $\mathrm{VERB}=$ verbalizer. Roman numerals indicate the formal class to which the verb or noun stem belongs (see $\$ 2.1$ ).
} 
direction, and valence, e.g. (1). In addition, pronominal direct objects are obligatorily incorporated into the verb, e.g. (2).

$$
\begin{aligned}
& \text { dIkarz̃ waha karırakokre } \\
& \text { dıkarə̃ waha ka-r-I-raks=kəre } \\
& \text { I } \quad \text { my.father 1-CTFG-TRANS-wait=FUT } \\
& \text { 'I will wait for my father.' }
\end{aligned}
$$

(2) waha riwarakokre

$$
\text { waha } \varnothing \text {-r-I-wa-raks=kəre }
$$

my.father 3-CTFG-TRANS- 1 -wait=FUT

'My father will wait for me.'

These prefixes include a well-developed system of voice and valence markers. There is a clear-cut morphological differentiation between transitive and intransitive verbs, and valence changes are always morphologically indicated. Furthermore, the language presents a complex set of mechanisms to indicate changes in the grammatical relations among the arguments of a verb. For example, any transitive verb, such as karo 'to cut', e.g. (3a), may be inflected to indicate the suppression of the agent, in a passive construction, e.g. (3b), or the suppression of the patient, in an antipassive construction, e.g. (3c).
a. nadI waritjore rade rikrorerI

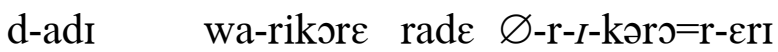
REL-mother 1-offspring hair 3-CTFG-TRANS-cut=CTFG-PROGR
'My mother is cutting my child's hair.'

b. waritjore rade rakrorerI

wa-ritfor $\varepsilon \quad$ rade $\varnothing$-r- $a$-kəro=r- $\varepsilon$ rI

1-offspring hair 3-CTFG-PASS-cut=CTFG-PROGR

'My child's hair is being cut.'

c. nadi rokrorerI

d-adi $\quad \varnothing$-r-ว-kəro=r-eri

REL-mother 3-CTFG-ANTI-cut=CTFG-PROGR

'My mother is cutting (something).'

The language also presents noun incorporation, which is generally a mechanism of possessor raising. In general, only inherently possessed nouns, such as body part terms, may be incorporated. Since only the possessed noun is incorporated, the valence of the incorporating verb remains unchanged, as the possessor is promoted to subject with intransitive verbs, or direct object with transitive 
Valence, Voice, and Noun Incorporation in Karajá

verbs, e.g. (4a). And since a transitive verb remains transitive after having incorporated a noun, it can still be made passive, e.g. (4b), or antipassive, e.g. (4c):

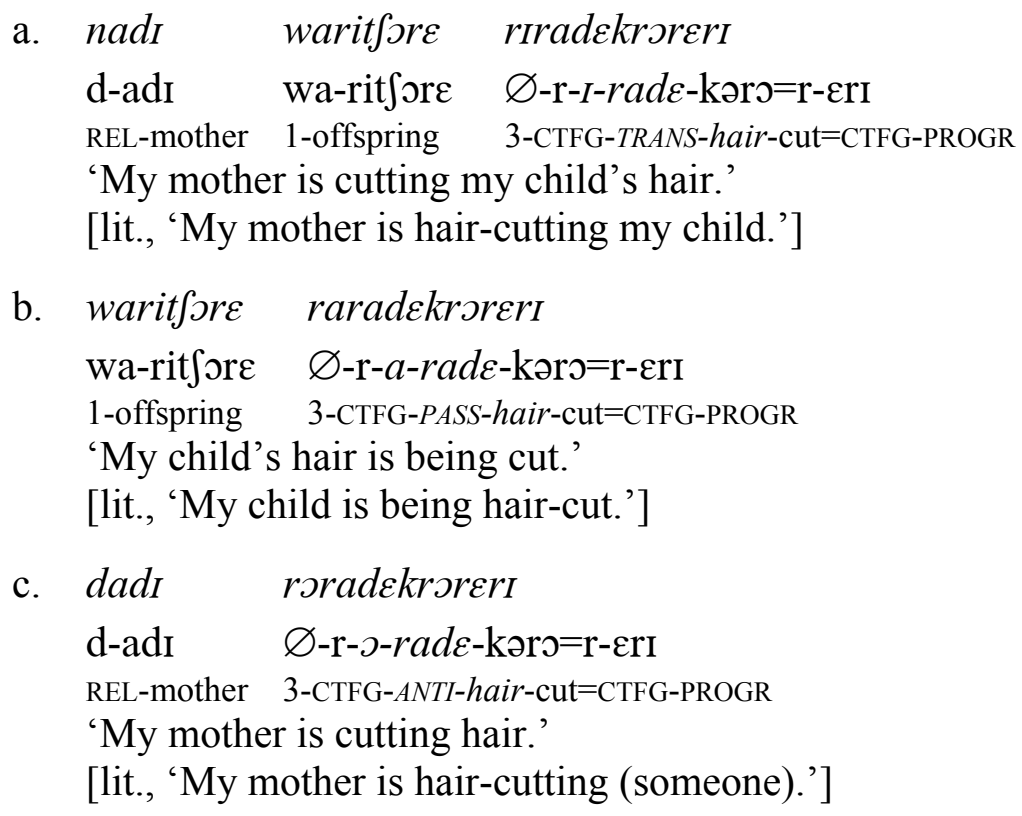

Examples such as (4c), in which antipassive markers can co-occur with an incorporated noun, may have interesting implications for theories that treat antipassive as a special kind of noun incorporation, such as seen in Baker's (1988) approach. If antipassive is merely a case of noun incorporation, as Baker claims, how would it interact with noun incorporation proper? The following section describes the morphosyntax of Karajá, in order to familiarize the reader with the mechanisms of grammatical relation changing in this language. Section 3 discusses the implications of the Karajá data for Baker's account of the antipassive construction.

\section{Morphosyntactic Overview}

Karajá is an SOV head-marking language. Core NP arguments - that is, subject and direct object-are not morphologically marked. Pronominal subjects are expressed by a series of free pronouns, such as dikarã 'I' in (1) above, while pronominal objects are expressed by a series of bound morphemes, such as $w a$ - ' 1 st person' in (2). In contrast to a fairly simple nominal morphology, Karajá presents a complex verb morphology. Stem formation processes such as compounding, noun incorporation, and reduplication are commonly used. In addition, as mentioned before, the verb is marked for person (and, cumulatively, mood), direction, and voice/valence. 
zero prefix, whereas Class I intransitive verbs, such as $d \partial d \partial k \varepsilon$ I 'to become hot', are marked by the prefix $a-:^{4}$

a. bəde rudədəra

bəde $\varnothing$-r- $\varnothing$-udədə=r-a

weather 3 -CTFG-INTR-become.cold=CTFG-PERF

'The weather got cold.'

b. bade radjdðkera

bəd $\varepsilon \quad \varnothing-\mathrm{r}-a-\mathrm{dodək} \varepsilon=\mathrm{r}-\mathrm{a}$

weather 3-CTFG-INTR-become.hot $=$ CTFG-PERF

'The weather got hot.'

Class II transitive stems, such as vahidz̃ II 'to treat', ${ }^{5}$ take the prefix $d$ - when not immediately preceded by a pronominal direct object or by an incorporated noun, e.g. (8a). When immediately preceded by a pronominal direct object or an incorporated noun, the relational prefix $l$ - is used, e.g. (8b):
a. hari waritfore riduahinãre

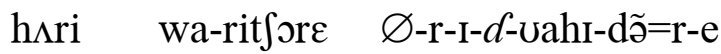
shaman 1-child 3-CTFG-TRANS-3/REL-medicine-VERB=CTFG-IMPERF
'The shaman treated my child.'

b. hari riwaluahinãre

hıri $\varnothing$-r-I-wa-l-vahI-dã =r-e

shaman 3-CTFG-TRANS-1-REL-medicine-VERB=CTFG-IMPERF

'The shaman treated me.'

\subsection{Subject Agreement}

Person agreement displays a strictly nominative pattern, with the verb always agreeing with the subject, be it intransitive (9a) or transitive (9b). Person agreement markers are distributed into two different sets, one occurring in the realis

\footnotetext{
${ }^{4}$ Maia (1998:28) terms the vowel that follows the directional prefix a thematic vowel, following an infelicitous tradition that traces back to Fortune and Fortune (1964). However, as we have seen, these vowels may be inflectional prefixes, marking voice and valence, e.g. (1)-(4), as well as person, e.g. (11). They can also be the result of the fusion between a person prefix and a voice prefix, e.g. (15a). Finally, they can be simply part of the verb stem, such as in the third person of Class II intransitive stems, e.g. (7a), (12a), (14a).

${ }^{5}$ This is a denominal verb derived from vahI II 'medicine' (cf. §1.4.1.1). It is tempting to consider the prefix $d$ - occurring with transitive verbs as simply a marker of third-person object. However, this prefix also occurs with antipassive constructions, e.g. (20), which do not allow explicit direct objects (see $\S 1.4 .2 .3$ ).
} 


\section{Eduardo Rivail Ribeiro}

(present and past tenses) and the other in the irrealis (future, potential, and admonitory). These prefixes are listed in Table 2 below. ${ }^{6}$

Table 2. Subject agreement markers in Karajá (Ribeiro 1996)

\begin{tabular}{ccc}
\hline Person & Realis & Irrealis \\
\hline $1^{\text {st }}$ & $a-$ & $q k a-/ \sigma^{\lambda}-$ \\
$2^{\text {nd }}$ & $d a-$ & $b \partial-/ b-$ \\
$3^{\text {rd }}$ & $\varnothing-$ & $\varnothing_{-} ;+k-/ \sigma_{-}+$ \\
\hline
\end{tabular}
a. kraritfakre
$k a-$-a-rika $=$ kəre
1 -CTFG-INTR-walk=FUT
'I will walk.'

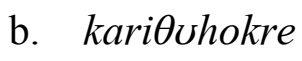

$k a-\mathrm{r}-\mathrm{I}-\varnothing-\theta$ uhə=kəre

1-CTFG-TRANS-3-wash=FUT

'I will wash it.'

\subsection{Direction}

The verb also inflects for direction, according to the speaker's point of view. Centrifugal direction ('thither'), marked by the prefix $r$ - or by its zero-allomorph, indicates that the process is seen as occurring away from the current location of the speaker, e.g. (10a). Centripetal direction ('hither'), marked by the prefix $d$-, indicates that the process is seen as occurring towards the current location of the speaker, e.g. (10b). Centrifugal direction is the unmarked member of the opposition. All verbs are marked for direction, including those that apparently do not indicate a motion whatsoever, such as $u r v$ 'to die' (cf. Ribeiro 2000b). Notice that the clitic aspectual auxiliaries also inflect for direction (cf. (3), (4), (7), (8) above), and, in the second person, also for person (cf. (15)).
a. kariwikre
ka-r-I- $\varnothing$-wi=kəre
1-CTFG-TRANS-3-carry=FUT
'I will take it.'

\author{
b. kadiwikre \\ ka- $d$-I- $\varnothing$-wi $=$ kəre \\ 1 -CTPT-TRANS-3-carry=FUT \\ 'I will bring it.'
}

\subsection{Valence and Voice}

Karajá verbs are lexically either transitive or intransitive. ${ }^{7}$ Intransitive verbs may have their valence increased through causativization (cf. §1.4.1.1) or through

\footnotetext{
${ }^{6}$ The same set of prefixes is used for singular and plural. There is also a distinction between a first person plural exclusive (marked by the same set of prefixes used for first person singular) and a first person plural inclusive (inflected for third person). The prefix $k a-$ ' $3{ }^{\text {rd }}$ person' is restricted to the centripetal direction of the irrealis mood.

${ }^{7}$ Maia (1998:79) mentions the existence of 'diffuse verbs' - that is, verbs that can be used either transitively or intransitively without any morphological alteration. In our data, however, the only verb he mentions as being diffuse, $v k \tilde{a}$ II 'to dry', has exactly the same behavior of other intransitive verbs, such as $v k a$ II 'to be cooked', e.g. (12). As shown in the example (b) below, this verb presents transitive morphology when used transitively. Notice that the transitive stem is a denomi-
} 


\section{Valence, Voice, and Noun Incorporation in Karajá}

oblique promotion (cf. §1.4.1.2). Transitive verbs, on the other hand, may have their valence decreased through reflexivization (cf. §1.4.2.1), passivization (cf. $\S 1.4 .2 .2$ ), and antipassivization (cf. §1.4.2.3).

\subsubsection{Intransitive Verbs}

Intransitive verbs are those that do not take a direct object as one of their arguments, such as udədə II 'to become cold', cf. (7a); dðdəke I 'to become hot', cf. (7b); and rika I 'to walk', cf. (9a). As we have seen above, Class I intransitive verbs are generally marked by the prefix $a$-, while Class II intransitive verbs are marked by a zero allomorph. In addition, a few intransitive verbs, such as $\theta \varepsilon$ 'to fall', are marked by the prefix $\varepsilon$-. The class of intransitive verbs includes not only one-place verbs such as rika I 'to walk' and udədə II 'to become cold', but also pseudo-transitive verbs such as obi II 'to see', whose arguments are oblique NPs - in this case, a locative, marked by the postposition $b \tilde{\partial}$ 'diffuse locative', e.g. (11). Although notionally transitive, such verbs behave as intransitive for all purposes. For example, they cannot be made passive or antipassive, and their arguments cannot be incorporated (16b).

\section{(11) dikar̃̃ halokวem̃̃ rabire

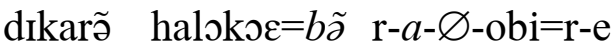 \\ I jaguar $=L O C \quad$ CTFG- 1 -INTR-See $=$ CTFG-IMPERF \\ 'I saw the jaguar.'}

Most intransitive verbs can be transitivized, either through causativization or through the promotion of an oblique to direct object. The transitivized stem is formed by the nominal form of the verb plus the verbalizer suffix $-d \tilde{\partial}$. This is illustrated in the example (12b) below, where the intransitive verb $v k a$ II 'to be cooked' is transitivized: ${ }^{8}$

nal verb formed by the deverbal noun ura 'the action of drying' followed by the verbalizer suffix - $d \tilde{\partial}$ (cf. §1.4.1):
(a) bec rukãre
be $\quad \varnothing-r-\varnothing-u k \tilde{\partial}=\mathrm{r}-\mathrm{e}$
water 3-CTFG-INTR-dry $=\mathrm{CTFG}$-IMPERF
'The water dried.'
(b) tfuu bee ridurãnãkre
du be $\quad \varnothing$-r-I-d-urə̃-d $=$ kəre
sun water 3-CTFG-TRANS-3/REL-dry-VB=FUT
'The sun will dry the water.'

\footnotetext{
${ }^{8}$ This example illustrates a very common process for deriving nouns from verb roots, namely consonantal replacement, which consists in replacing a velar stop or a glottal fricative occurring in the last syllable of the verb root with an alveolar flap: rika I 'to walk' > rira 'the action of

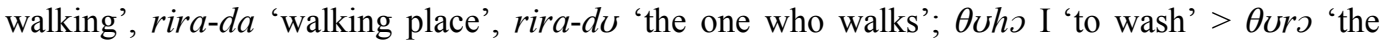
action of washing', Ouro-da 'washing material', Auro-du 'the one who washes' (Ribeiro 1996). Thus, the transitive stem in (12b) above is constructed with the nominal form of the verb $v k a$ 'to be cooked', ura 'the action of cooking', followed by the verbalizer suffix $-d \tilde{\partial}$.
} 
a. iweru rukarerI

iweru $\varnothing$-r- $\varnothing-u k a=\mathrm{r}-\varepsilon \mathrm{rI}$

calugi 3-CTFG-INTR-be.cooked=CTFG-PROGR

'The calugi (a kind of drink) is cooking.'

b. ahawaki iweru riduranãkre

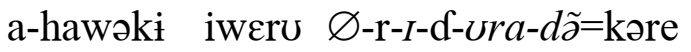

2-woman calugi 3-CTFG-TRANS-3/REL-be.cooked-VERB=FUT

'Your wife will cook the calugi.'

\subsubsection{Causativization}

Causative stems derived from unergative verbs, such as rika I 'to walk', are

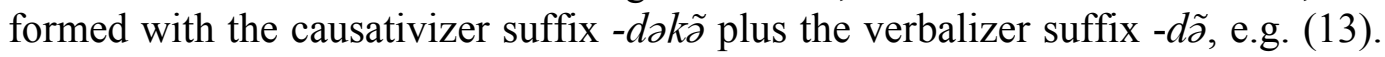
However, the causative suffix does not occur in causative stems derived from unaccusative verbs, such as $v k a$ II 'to be cooked' in (12b) above.

$$
\begin{aligned}
& \text { habu kuladu ririradəkãnãrerI }
\end{aligned}
$$

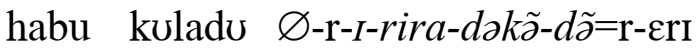

$$
\begin{aligned}
& \text { man child 3-CTFG-TRANS-walk-CAUS-VERB=CTFG-PROGR }
\end{aligned}
$$

'The man is making the child walk.'

\subsubsection{Oblique Promotion}

With a few pseudo-transitive verbs which take an allative or dative argument, such as $\tilde{\partial} \tilde{\partial} r a \theta i$ II 'to ask', transitivization results in the promotion of the former oblique argument to direct object (examples from the Xambioá dialect):
a. hawiki darikorcks rãkãrafire

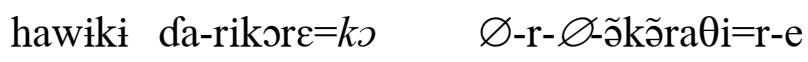
woman 3 REFL-offspring $=A L \quad 3$-CTFG-INTR-ask=CTFG-IMPERF
'The woman asked her son.'
b. hawiki darikore ridãkãrafinãre

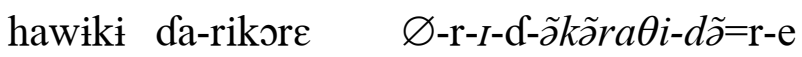
woman 3REFL-offspring 3-CTFG-TRANS-3/REL-ask-VERB=CTFG-IMPERF
'The woman questioned her son.'

\subsubsection{Transitive Verbs}

Transitive verbs are those that take a direct object as one of their arguments. In Karajá, transitive verbs are always marked by the prefix $I^{-}$, as shown in examples (1)-(4) above. Both transitive and intransitive valence prefixes may fuse with the preceding personal prefix under certain circumstances, such as in the second person in the centrifugal direction of the realis mood (15a). Notice that there is no fusion in the centripetal direction (15b). 

a. derakode
b. dadirakode
da- $\varnothing-I-\varnothing-$ rako $=\mathrm{d}-\mathrm{e}$
da-d-I- $\varnothing$-raks $=$ d-e
2-CTFG-TRANS-3-wait=2-IMPERF
2-CTPT-TRANS-3-wait=2-IMPERF
'You waited for him (thither).'
'You waited for him (hither).'

\subsubsection{Reflexive}

There are two allomorphs of the reflexive morpheme, $e \theta i$ - and $i \theta i$-. The former is incorporated into the verb, when the NP coreferential with the subject is a direct object (16a). The latter is attached to postpositions, when the coreferential NP is an oblique (16b).
a. dikarz̃ karefïuhokre
dikarə̃ ka-r-e $\theta i-\theta u h o=k ə r e$
I 1-CTFG-REFL-wash=FUT
'I will wash myself.'
b. habu ifim̃ robire
habu $\mathrm{i} \theta \mathrm{i}=\mathrm{b} \tilde{\mathrm{a}} \quad \varnothing-\mathrm{r}-\varnothing$-obi=r-e
man $\quad$ REFL $=$ LOC 3 -CTFG-INTR-See $=$ CTFG-IMPERF
'The man saw himself.'

\subsubsection{Passive}

Passive verbs are marked by the prefix $a$-, with Class I stems such as $\theta$ uhs 'to wash' (17b), or its zero allomorph, with Class II stems, such as uka 'to split' (18b). Notice that this is apparently the same prefix that occurs with basic intransitive verbs such as rika I 'to walk' and obi II 'to see'. With transitive roots, however, this prefix will always convey a passive or anticausative meaning.

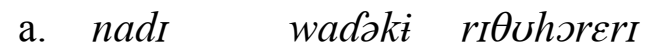

d-adi wa-dəki $\varnothing$-r-I- $\quad$ uho=r-eri

REL-mother 1-clothes 3-CTFG-TRANS-wash=CTFG-PROGR

'My mother is washing my clothes.'

b. wadjki räuhorerI

wa-dəki $\varnothing$-r- $a-\theta u h o=r-\varepsilon r I$

1-clothes 3-CTFG-PASS-wash=CTFG-PROGR

'My clothes are being washed.'

\footnotetext{
a. kodu halokse koru ritfukare

kodu halokoe koru $\varnothing$-r-I-d-uka=r-e

turtle jaguar forehead 3-CTFG-TRANS-3/REL-split=CTFG-IMPERF

'The turtle split the jaguar's forehead.'
} 


\section{b. halıkse koru rukare \\ halokoe koru $\varnothing$-r- $\varnothing$-uka=r-e \\ jaguar forehead 3-CTFG-PASS-split=CTFG-IMPERF \\ 'The jaguar's forehead was split.'}

In the passive construction, the original $\mathrm{O}^{9}$ becomes the subject, as it happens in languages such as English, for example. However, unlike English, where the agent in a passive construction can be expressed as an oblique ('by-phrase'), in Karajá, the agent, although sometimes implicit, cannot be expressed at all. Thus, passives in Karajá are both a backgrounding construction, functioning to delete unknown or irrelevant subjects, and a foregrounding construction, since it results in the promotion of the original $O$ to subject position (Foley and Van Valin 1985).

\subsubsection{Antipassive}

Antipassive is a phenomenon typical of ergative languages, corresponding functionally to a 'mirror image' of the passive construction in nominative-accusative languages (Silverstein 1976). In a syntactically ergative language, "while the A and the $\mathrm{O}$ in an ergative clause are marked as ergative and absolutive respectively, the A in an antipassive is typically coded as an absolutive NP, and the $\mathrm{O}$ (if present) appears in a case other than the absolutive" (Cooreman 1994:50). Although some authors, such as Cooreman, limit the discussion of antipassive constructions to ergative languages, nominative-accusative languages may also present backgrounding antipassives, which "function to demote the undergoer to peripheral status" (Foley and Van Valin 1985:338). This is what occurs in Karajá, where antipassive, marked by the prefix ${ }^{-}$, results in the deletion of an unknown or irrelevant direct object:

$$
\begin{aligned}
& \text { nadI rotuhorerI } \\
& \text { d-adi } \quad \varnothing \text {-r-o- } \theta u h \jmath=r-\varepsilon r I
\end{aligned}
$$

'My mother is washing (something).'

$$
\begin{aligned}
& \text { habu rotfukarerI } \\
& \text { habu } \varnothing \text {-r-o-d-uka=r-ErI } \\
& \text { man 3-CTFG-ANTI-3/REL-split=CTFG-PROGR } \\
& \text { 'The man is splitting (something).' }
\end{aligned}
$$

As these examples show, antipassive in Karajá is not promotional (or foregrounding), in the sense that the A remains in the same syntactic relation it occupies in the corresponding active, transitive voice. Furthermore, the antipas-

\footnotetext{
${ }^{9}$ I will follow Cooreman in adopting Dixon's (1979) use of the labels A and O to refer to the two participants in a two-participant clause - prototypically, the agent and the patient, respectively.
} 
Valence, Voice, and Noun Incorporation in Karajá

sive construction in Karajá does not allow the expression of the demoted $\mathrm{O}$ whatsoever, which is an interesting parallel with what occurs to the agent in the passive construction.

\subsection{Noun Incorporation}

Noun incorporation in Karajá is a process by which the head of the absolutive noun phrase is inserted into the verb, thereby forming a compound. The more productive pattern of noun incorporation involves only body part terms, which are in general inherently possessed nouns. ${ }^{10}$ Since only the head of the absolutive noun phrase is incorporated, the valence of the resulting noun-verb compound remains unaltered, as the possessor is promoted to subject with intransitive, unaccusative verbs such as bohə I 'to break', e.g. (21), or to object with transitive verbs such as $d \partial k a$ I 'to tie', e.g. (22): ${ }^{11}$
a. iñ̃we rIkI dai rabohore
idã $w \varepsilon$ rrki dai $\varnothing$-r-a-bohs=r-e
people belly NARR 3.LOC 3-CTFG-INTR-break=CTFG-IMPERF
'The people's bellies were broken there, it is said.'
b. iñ rikI dai rawebohore

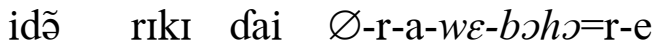
people NARR 3.LOC 3-CTFG-INTR-belly-break=CTFG-IMPERF
'The people's bellies were broken there, it is said.'

\footnotetext{
${ }^{10}$ Karajá also presents classificatory noun incorporation. In such cases, the incorporated items are body part terms that ordinarily function as measure terms, e.g. (a), such as ra 'head' (measure term for potatoes and yams), $r u$ 'eye' (measure term for grains), and $w \varepsilon$ 'belly' (measure term for round fruits):
}
(a) anõna i-we-Oohodzi
adõda $\quad \mathrm{I}-w \varepsilon$ - $\theta$ ohodi

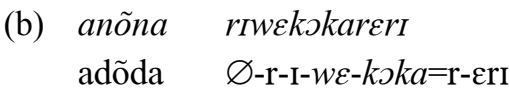
pineapple 3-belly-one
'one pineapple'
pineapple 3-CTFG-TRANS-belly-grate $=\mathrm{CTFG-PROGR}$ ' $\mathrm{He} / \mathrm{she}$ is grating pineapple.'

${ }^{11}$ Examples (21a) and (21b) are from the Javaé dialect. Although Maia (1998:63) claims that object incorporation does not occur in Javaé, noun incorporation seems to be as common in Javaé as it is in the other three dialects. The example below, involving the incorporation of the noun dikshu I 'knee' to the transitive verb we I 'to penetrate', occurs in the same text from which the examples above were obtained:
(a) ridikshuwere,
Idikshu riwere
$\varnothing$-r-I- $\varnothing$-dikshu-wE=r-e
$\mathrm{I}-d i k s h v \quad \varnothing$-r-I-wE $=\mathrm{r}-\mathrm{e}$
3-CTFG-TRANS-3-knee-penetrate $=$ CTFG-IMPERF 3-knee
' $[\mathrm{He}]$ stabbed him in the knee, he stabbed his knee.'
3-CTFG-TRANS-penetrate $=\mathrm{CTFG}-\mathrm{IMPERF}$ 
Eduardo Rivail Ribeiro
a. kañ̃fiwe kuӨehewedi ridakare

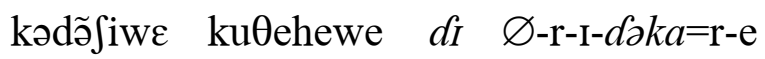
K. rhea leg 3-CTFG-TRANS-tie=CTFG-IMPERF
'Kynyxiwè tied the legs of the rhea.'
b. kañ̃fiwe kuӨehewe rididakare

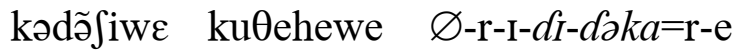
K. rhea 3-CTFG-TRANS-leg-tie=CTFG-IMPERF
'Kynyxiwè tied the legs of the rhea.'

As we have seen in (4) above, since noun incorporation is a valencepreserving process, an incorporating transitive verb can still be made passive or antipassive. The following section discusses the implications of the interaction between noun incorporation and antipassive in Karajá for Baker's incorporating theory of antipassive.

\section{Antipassive and Noun Incorporation}

In this section, I will discuss the problems that the co-occurrence of antipassive and noun incorporation may potentially pose to an incorporating analysis of antipassive, taking into consideration the description of Karajá morphosyntax sketched above. Adopting the theoretical framework of Government and Binding theory, Baker (1988) proposes a treatment of familiar grammatical function changing processes such as passive, possessor raising, and applicatives as a matter of incorporation, taking incorporation in a rather broad sense, as "processes by which one semantically independent word comes to be 'inside' another" (1). Instead of explicit rules which would account separately for each grammatical function changing process, Baker claims that "the heart of all apparent GF changing processes is the movement of a word or (more technically) a lexical category" (19). Thus, Baker claims that words, and not only phrases, can be moved, a process he terms $\mathrm{X}^{0}$ movement, an instance of the generalized movement transformation Move-Alpha. ${ }^{12}$

Baker's incorporation theory provides a unifying account for a number of apparently distinct grammatical function changing processes. Thus, while applicatives are seen as cases of adpositional incorporation, antipassive is treated as a matter of noun incorporation, along with noun incorporation proper and possessor raising reanalysis. According to Baker (1988:133), "antipassive is merely a special case of Noun Incorporation in which a single, designated lexical item incorporates." The antipassive morpheme, which semantically corresponds to an indefinite NP, is generated in the direct object position at D-structure and then adjoined to the verb by $\mathrm{X}^{0}$ movement. As is typical in Government and Binding

\footnotetext{
${ }^{12}$ Given limitations of space, the summary of Baker's theory presented here is necessarily succinct. My purpose in this section is not to provide an extensive discussion of his theory, but simply to point out its inadequacy to explain the Karajá data.
} 
theory, the movement leaves a trace, which must be coindexed with the moved element in order to satisfy the Empty Category Principle (ECP), according to which traces must be properly governed.

In some languages, however, antipassive markers can co-occur with an incorporated noun. Karajá, as we have seen, is one of these languages. Cases such as these raise an interesting question concerning the way antipassive and noun incorporation proper would interact in an incorporating account of antipassive. Baker (1988:138) mentions the case of Nisgha, cf. (23), as well as the Mayan languages as languages where antipassive marking occurs with an incorporated noun. According to him, in these languages, the antipassive morpheme "acts as a kind of 'linking morpheme' which appears when the object noun root is incorporated into the verb." The antipassive "provides the theta role link necessary for Noun Incorporation to take place" (139). Baker apparently does not consider examples such as (23) as cases of double NI, since both the antipassive affix and the incorporated noun share one and the same thematic relation.

Nisgha (Baker 1988:138)

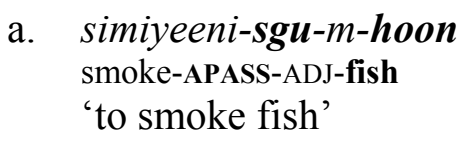
b. lits'il-sgu-m-daala count.up-APASS-ADJ-money 'to keep track of money (donations)'

All the examples cited by Baker seem to involve cases in which noun incorporation is a valence-changing process, making intransitive an otherwise transitive verb. In such cases, antipassive marking seems to be merely a consequence of the fact that the verb is made intransitive by the incorporation of its object. However, this is quite different from what happens in Karajá, where, as we have seen, productive noun incorporation is always a valence-preserving process. In cases in which the antipassive marker occurs with an incorporated noun, it is clear that the implied direct object corresponds to the original possessor of the incorporated noun (4c). If antipassive is indeed a case of noun incorporation, it is necessary to admit that, in examples such as this, antipassivization would have to be preceded by noun incorporation proper, which would place the antipassive morpheme in direct object position, making it eligible for incorporation.

In principle, this fact would apparently not be problematic for Baker's approach, since, according to him, the antipassive does not necessarily affect only structural direct objects (Baker 1988:136). The antipassive morpheme may correspond, for example, to the subject of a lower clause, which is then moved up to a higher clause in a Raising-to-Object construction. This is what happens in Chamorro:

(24) Chamorro (Baker 1988:137)

Kao man-ekspekta hao pära un ma'-ayuda?

Q APASS-expect you(ABS) IRREAL-2S-PASS-help

'Do you expect someone to help you?' 


\section{Eduardo Rivail Ribeiro}

Thus, one might likewise postulate that in Karajá, the antipassive morpheme could be generated as a possessor, which would be promoted to direct object through the incorporation of the possessed noun. The new object would then be incorporated into the verb, through antipassivization. However, Baker categorically rules out the possibility of multiple noun incorporations:

Both case theory and the ECP rule out acyclic combinations, where first a noun incorporates into the verb and then the possessor itself incorporates - even though that possessor will look like a direct object on the surface given the GTC. (Baker 1988:374) $)^{13}$

According to the Government Transparency Corollary (GTC), "a lexical category which has an item incorporated into it governs everything which the incorporated item governed in its original structural position" (64). Thus, the incorporation of the former possessor should in principle be possible, since it now behaves as the direct object. However, Baker (367) argues that acyclic combinations would violate the proper government required by the ECP. According to this notion of government, intervening traces (such as the one left by an incorporated noun or adposition) and not only full lexical items can act as 'possible antecedents,' blocking the incorporation of the new direct object into the verb.

Nevertheless, such a scenario is exactly what happens in Karajá, where noun incorporation-which is essentially a possessor raising construction-clearly feeds antipassive. ${ }^{14}$ Therefore, if antipassive is, in fact, a matter of noun incorporation, Karajá provides a strong counterexample to Baker's claim that multiple noun incorporations do not occur. This apparently raises the necessity for a revision of Baker's approach in order to allow repeated applications of noun incorporation.

\section{Final Remarks}

This paper presents a reanalysis of the Karajá verb, revealing a complex set of grammatical relation changing mechanisms, such as antipassive and noun incorporation, which were not mentioned in previous studies of the language (Fortune and Fortune 1964, Maia 1998). In particular, the interaction between antipassive and noun incorporation in Karajá has interesting implications for Baker's (1988) incorporating account of antipassive, providing a strong counterexample to his claim against the occurrence of multiple incorporations.

\footnotetext{
${ }^{13}$ Acyclic combinations are those resulting from a movement which "reaches down more deeply into the structure than the first one does" (Baker 1988:365).

${ }^{14}$ As Baker admits, possessor raising constructions are the most likely to yield interactions between different NIs, "because by definition there are two NPs present: the possessor and the NP headed by the possessed noun." Therefore, one would expect possessor raising to feed "Noun Incorporation proper, Antipassivization, or even Possessor Raising itself, since each of these processes is known to involve the verb and its direct object." However, Baker considers such combinations "systematically impossible" (Baker 1988:375).
} 
Valence, Voice, and Noun Incorporation in Karajá

\section{References}

Baker, Mark C. 1988. Incorporation: A Theory of Grammatical Function Changing. Chicago: University of Chicago Press.

Cooreman, Ann. 1994. A Functional Typology of Antipassives. In Barbara Fox and Paul J. Hopper (eds.), Voice: Form and Function. Amsterdam: John Benjamins, 49-87.

Dixon, Robert M. W. 1979. Ergativity. Language 55:59-138.

Foley, William, and Robert Van Valin, Jr. 1985. Information Packaging in the Clause. In Timothy Shopen (ed.), Language Typology and Syntactic Description 1:282-364. Cambridge University Press.

Fortune, David, and Gretchen Fortune. 1964. Karajá Grammar. Ms., Arquivo Lingüístico do Museu Nacional, Rio de Janeiro.

Maia, Marcus. 1998. Aspectos Tipológicos da Língua Javaé. München: Lincom Europa.

Ribeiro, Eduardo R. 1996. Morfologia do verbo Karajá. M.A. thesis, Universidade Federal de Goiás.

Ribeiro, Eduardo R. 2000a. [ATR] Vowel Harmony and Palatalization in Karajá. Santa Barbara Papers in Linguistics, Vol. 10: Proceedings of WAIL 2000. Santa Barbara: University of California, Santa Barbara, 80-92.

Ribeiro, Eduardo R. 2000b. Direction in Karajá. Paper presented at the VI Encuentro de Lingüística en el Noroeste. Sonora, México: Universidad de Sonora.

Rodrigues, Aryon D. 1994. Grammatical Affinity among Tupí, Karíb, and MacroJê. Ms., Universidade de Brasília.

Silverstein, Michael. 1976. Hierarchy of Features and Ergativity. In R. M. W. Dixon (ed.), Grammatical Categories in Australian Languages. Canberra: Australian Institute of Aboriginal Studies.

Wiesemann, Ursula. 1986. The Pronoun Systems of Some Jê and Macro-Jê Languages. In U. Wiesemann (ed.), Pronominal Systems. Tübingen: Gunther Narr Verlag, 359-80.

Department of Linguistics

University of Chicago

1010 E. $59^{\text {th }}$ Street

Chicago, IL 60637

erribeir@midway.uchicago.edu 